\section{Prognostic value of the post-training oxygen uptake efficiency slope in patients with coronary artery disease}

\author{
Roselien Buys ${ }^{1,2, *}$, Ellen Coeckelberghs', \\ Véronique A Cornelissen', Kaatje Goetschalckx ${ }^{3}$ \\ and Luc Vanhees'
}

European Journal of Preventive Cardiology 0(00) I-9

(C) The European Society of Cardiology 2016

Reprints and permissions: sagepub.co.uk/journalsPermissions.nav DOI: I0.I I77/20474873 I6643446 ejpc.sagepub.com

@SAGE

\begin{abstract}
Background: Peak oxygen uptake is an independent predictor of mortality in patients with coronary artery disease (CAD). However, patients with CAD are not always capable of reaching peak effort, and therefore submaximal gas exchange variables such as the oxygen uptake efficiency slope (OUES) have been introduced. Baseline exercise capacity as expressed by OUES provides prognostic information and this parameter responds to training. Therefore, we aimed to assess the prognostic value of post-training OUES in patients with CAD.

Methods: We included 960 patients with CAD (age 60.6 \pm 9.5 years; 853 males) who completed a cardiac rehabilitation program between 2000 and 20II. The OUES was calculated before and after cardiac rehabilitation and information on mortality was obtained. The relationships of post-training OUES with all-cause and cardiovascular (CV) mortality was assessed by Cox proportional hazards regression analyses. Receiver operator characteristic curve analysis was performed in order to obtain the optimal cut-off value.

Results: During $7.37 \pm 3.20$ years of follow-up (range: $0.45-13.75$ years), 108 patients died, among whom 47 died due to CV reasons. The post-training OUES was related to all-cause (hazard ratio: $0.50, p<0.00 \mathrm{I}$ ) and CV (hazard ratio: 0.40 , $p<0.00$ I) mortality. When significant covariates, including baseline OUES, were entered into the Cox regression analysis, post-training OUES remained related to all-cause and CV mortality (hazard ratio: $0.40, p<0.01$ and 0.26 , $p<0.0$ I, respectively). In addition, the change in OUES due to exercise training was positively related to mortality (hazard ratio: $0.49, p<0.01$ ).

Conclusion: Post-training OUES has stronger prognostic value compared to baseline OUES. The lack of improvement in exercise capacity expressed by OUES after an exercise training program relates to a worse prognosis and can help distinguish patients with favorable and unfavorable prognoses.
\end{abstract}

\title{
Keywords
}

Coronary artery disease, cardiac rehabilitation, oxygen uptake efficiency slope, mortality

Received 30 November 2015; accepted 17 March 2016

\section{Introduction}

Exercise capacity, as expressed by peak oxygen uptake (peak $\mathrm{VO}_{2}$ ), is an independent predictor of all-cause and cardiovascular (CV) mortality in patients with coronary artery disease (CAD), meaning that patients with an impaired exercise capacity are at higher risk of fatal (cardiac) events. ${ }^{1-4}$ For many years, the gold standard for the measurement of aerobic exercise capacity has been peak $\mathrm{VO}_{2}{ }^{2,5,6}$ However, we recently showed that almost $12 \%$ of patients with CAD are unable to perform a truly maximal exercise test. ${ }^{7}$ In this subset of

\footnotetext{
'Department of Rehabilitation Sciences, KU Leuven, Leuven, Belgium ${ }^{2}$ Department of Cardiovascular Sciences, KU Leuven, Leuven, Belgium ${ }^{3}$ Department of Cardiovascular Diseases, University Hospitals of Leuven, Leuven, Belgium

*These authors contributed equally.

\section{Corresponding author:}

Roselien Buys, Department of Rehabilitation Sciences Tervuursevest I0I, B I50I B 300I Leuven, Belgium.

Email address: roselien.buys@faber.kuleuven.be
} 
patients, peak $\mathrm{VO}_{2}$ might be less meaningful for determining cardiorespiratory response to exercise.

For this reason, several submaximal exercise variables have been proposed as alternative measures for assessing exercise capacity in different patient populations. The advantage of these submaximal exercise variables is that they can be determined even when the exercise test is interrupted prematurely and are therefore not limited by medical, motivational or subjective factors. One of those parameters is the oxygen uptake efficiency slope (OUES), which is a marker of cardiorespiratory functional reserve that represents the relationship between minute ventilation (VE) and oxygen uptake $\left(\mathrm{VO}_{2}\right)$ during graded exercise. ${ }^{8-10}$ The OUES is an established measure of exercise capacity in patients with cardiac diseases. ${ }^{8,11-14}$ Furthermore, it seems to be the preferred alternative measure for peak $\mathrm{VO}_{2}$ in case of submaximal exercise testing, since it correlates highly with peak $\mathrm{VO}_{2}$ and it has high test-retest reliability. ${ }^{13,15-17}$

Structured cardiac rehabilitation programs result in significant improvements in exercise capacity ${ }^{10,12,15}$ and survival in patients with cardiac diseases..$^{10,12,15,18-22}$ It has been shown that the OUES responds to training and that this training-induced change in OUES correlates significantly with the change in peak $\mathrm{VO}_{2}$ after training. ${ }^{10,23,24}$ Furthermore, previous research provided evidence for a stronger prognostic value of post-training exercise capacity when compared to baseline exercise capacity. ${ }^{25}$ Therefore, it seems justified to investigate the prognostic value of the post-training OUES and the training response in cardiac patients.

\section{Materials and methods}

\section{Study population}

All patients with CAD who completed the outpatient cardiac rehabilitation program for the first time at the University Hospitals Leuven (Belgium) between January 2000 and March 2011 were retrospectively included in the study. CAD was defined by a recent history of acute myocardial infarction, percutaneous coronary intervention or coronary artery bypass surgery. Patients were not included if they presented with exercise-induced myocardial ischemia and/or malignant ventricular arrhythmias. Moreover, CAD patients with congenital heart disease, pacemakers or implantable cardioverter defibrillators were excluded. The study was approved by the local ethical committee. General and demographic information, exercise testing data, drug treatment and the presence of $\mathrm{CV}$ risk factors were collected at the time of enrollment in the rehabilitation program. This included clinical anamnesis for the detection of the familial predisposition for heart disease, history of diabetes, history of hypertension and smoking habits. Blood pressure and body mass index were objectively measured and current drug treatment was registered by the prescribing physician.

\section{Cardiopulmonary exercise test}

Graded exercise tests were performed on a cycle ergometer (Siemens-Elema 380B; Ergometrics $800 \mathrm{~S}$, Ergometrics, Bitz, Germany) in an air-conditioned laboratory where the room temperature was regulated at $18-22^{\circ} \mathrm{C}$. Patients were asked to cycle at a constant pace of $60 \mathrm{rpm}$. The initial workload of $20 \mathrm{~W}$ was increased by $20 \mathrm{~W}$ every minute. Blood pressure was measured at rest with the patient sitting on the bicycle and every 2 minutes during graded exercise. Heart rate and a 12-lead electrocardiogram (Max Personal Exercise Testing ${ }^{\circledR}$, Marquette, WI, USA) were registered continuously. Inspired and expired gasses were analysed breath by breath by means of the Oxycon Pro (Jaeger, Mijnhardt, The Netherlands). All patients were asked to perform a graded exercise test until exhaustion or until symptoms appeared. Exhaustion was defined by the patients, based on feelings of exhaustion, dyspnea, pain and/or tiredness in the legs. Peak values were defined as the 30 second average at the highest workload achieved during the cardiopulmonary exercise test (CPET). Peak $\mathrm{VO}_{2}$ was compared to predicted normal values. ${ }^{6}$ Peak respiratory exchange ratio (RER) was calculated by dividing peak carbon dioxide $\left(\mathrm{VCO}_{2}\right)$ by peak $\mathrm{VO}_{2}$.

Respiratory data were averaged every 15 seconds. The first minute of exercise was excluded because of the often very irregular breathing pattern at the onset of exercise. Robust regression was used for the calculation of the OUES in order to account for possible outliers. The OUES was determined from the relation $\mathrm{VO}_{2}=a \log _{10} \mathrm{VE}+b$, where $a$ is the OUES and $b$ is the intercept. ${ }^{8}$ Results for the OUES were compared to the body surface area-adjusted predicted normal values based on the equations proposed by Buys et al. ${ }^{26}$ for patients under 60 years of age and by Hollenberg and Tager $^{9}$ for patients aged 60 years and older.

CPETs were performed at baseline and after 3 months of cardiac rehabilitation. In order to take into account the baseline values, changes in exercise parameters were expressed as percentages of change as follows: ((post-training variable - pre-training variable)/ pre-training variable $) \times 100$.

\section{Training intervention}

All patients were enrolled in a standard ambulatory, supervised, 12-week cardiac rehabilitation program consisting of three training sessions a week. Each training 
session consisted of 60 minutes of aerobic exercises including cycling, running, arm ergometry, rowing and standing calisthenics, followed by 30 minutes of muscle strengthening exercises and relaxation exercises on the ground. Exercise intensity was individually determined for each patient based on the first CPET using the Karvonen formula (target training heart rate $=$ (resting heart rate $+60 \%$ to $90 \%$ (peak heart rate - resting heart rate))) and progressively increased throughout the rehabilitation period.

\section{Follow-up}

The primary endpoint of the study was all-cause mortality; CV mortality was the secondary endpoint. Information about the vital status, date and cause of death of the patients was obtained by consulting the patients' medical files. If no patient contact was registered in these files during the last 6 months, the patients' general practitioners (GPs) were contacted by post. The follow-up period ended on 31 January 2014. The overall response rate was $89 \%$. Deaths were coded according the International Classification of Diseases (ICD-code), ninth revision. ${ }^{27}$

\section{Statistical analyses}

SAS statistical software version 9.3 for Windows (SAS Institute, Inc., Cary, NC, USA) was used for descriptive and survival analyses. GraphPad Prism 6.0 (GraphPad Software, San Diego, CA, USA) was used to plot the figures and perform receiver operator characteristic (ROC) curve analyses. Data are reported as mean value $\pm \mathrm{SD}$ or number (percentage). Distributions were checked for normality with the Shapiro-Wilk statistic. Comparisons between groups were performed by unpaired $t$-test and chi-square contingency analysis. Differences between baseline and post-intervention values were investigated by paired $t$ tests. The response to training of the OUES was calculated by subtracting the OUES before intervention from the OUES after intervention and is reported both in absolute values and as percentage changes. The Cox proportional hazards regression model was used for survival analysis. ${ }^{28}$ Relative hazard rates with $95 \%$ confidence limits are reported for single and multiple regression analysis. All patient characteristics, risk factors and exercise parameters were included in the single Cox regression model. The significant univariate predictors of mortality were then further added to the multivariate Cox regression model. Variables included in the multivariate analysis were post-training OUES, age, gender, history of diabetes and baseline OUES. History of diabetes was coded 0 when the condition was absent and 1 when it was present. Furthermore, ROC curve analysis was performed in order to define the optimal cut-off value of the training-induced change in OUES. This value was chosen according to the highest sum of sensitivity and specificity. Statistical results were considered significant if $p<0.05$.

\section{Results}

\section{Patient characteristics and exercise parameters}

A flowchart of patient inclusion in the study is provided in Figure 1. Between January 2000 and March 2011, 1078 Caucasian CAD patients completed the ambulatory cardiac rehabilitation program. Vital status at the end of the follow-up period could be tracked in 960 patients, and 118 patients were lost to follow-up for the following reasons: GP retired $(n=20)$, died $(n=12)$ or not willing to cooperate $(n=8)$, patients changed their GP $(n=5)$ or no response was received $(n=73)$. There were no significant differences between the patients who were lost to follow-up and the included patients regarding baseline and training parameters. The total follow-up period was 7057

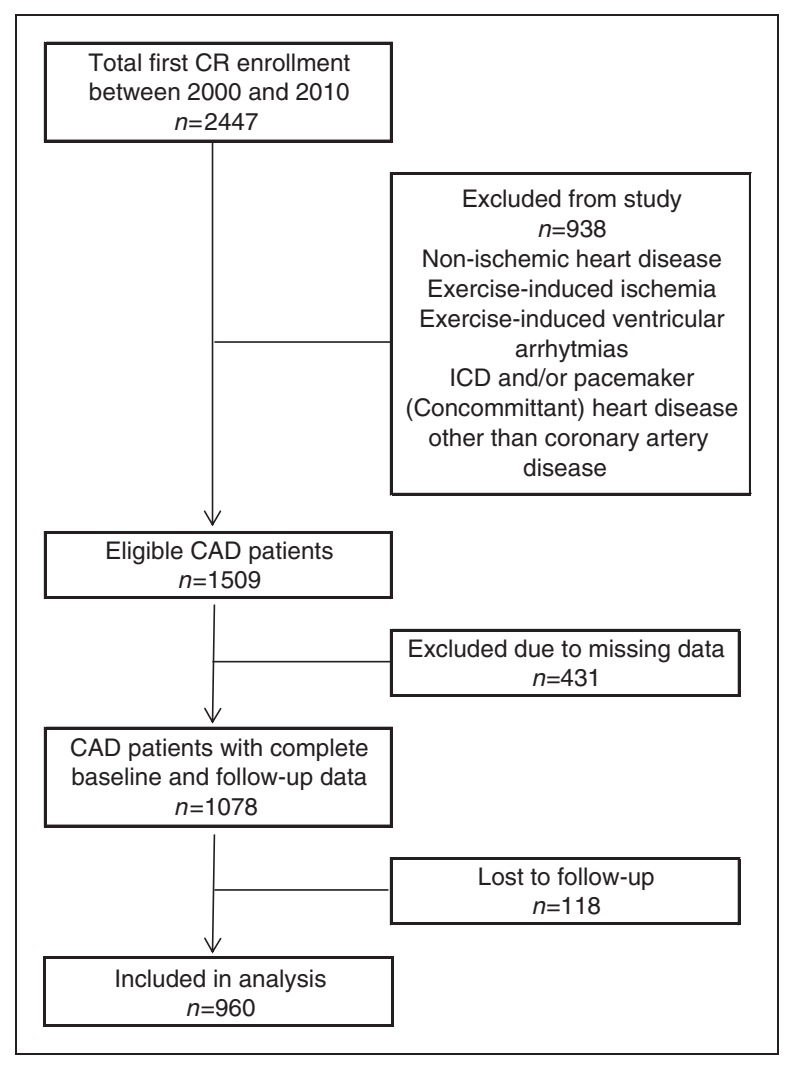

Figure I. Flow chart of patient inclusion and exclusion criteria for the study.

CR: cardiac rehabilitation; ICD: implantable cardioverter defibrillator; CAD: coronary artery disease. 
Table I. Clinical characteristics of the patients at entry of the study.

\begin{tabular}{|c|c|c|c|c|}
\hline Characteristic & $\begin{array}{l}\text { Overall } \\
(n=960)\end{array}$ & $\begin{array}{l}\text { Survivors } \\
(n=855)\end{array}$ & $\begin{array}{l}\text { Non- } \\
\text { survivors }^{\mathrm{a}} \\
(n=105)\end{array}$ & RHR \\
\hline Male gender & $833(87)$ & $738(86)$ & $95(90)$ & 0.76 \\
\hline Age (years) & $60.6 \pm 9.5$ & $60.2 \pm 9.4$ & $64.3 \pm 9.7 * * *$ & k $1.06 * * * *$ \\
\hline Weight (kg) & $79.3 \pm 12.2$ & $279.3 \pm 11.8$ & $379.5 \pm 15.0$ & 1.004 \\
\hline BMI $\left(\mathrm{kg} / \mathrm{m}^{2}\right)$ & $26.9 \pm 3.7$ & $26.9 \pm 3.6$ & $26.9 \pm 4.1$ & 1.016 \\
\hline $\begin{array}{l}\text { Resting } \\
\text { heart rate } \\
\text { (beats/minute) }\end{array}$ & $63 \pm 11$ & $65 \pm 12$ & $67 \pm 11$ & 1.01 \\
\hline $\begin{array}{l}\text { Resting SBP } \\
\quad(\mathrm{mmHg})\end{array}$ & $130 \pm 20$ & $130 \pm 19$ & $136 \pm 20 * *$ & 1.01 \\
\hline $\begin{array}{l}\text { Resting DBP } \\
(\mathrm{mmHg})\end{array}$ & $73 \pm 12$ & $73 \pm 12$ & $75 \pm 13$ & 1.01 \\
\hline \multicolumn{5}{|l|}{ Treatment } \\
\hline Beta-blockade & $839(87)$ & $746(87)$ & 93 (89) & 1.06 \\
\hline Diuretics & $143(15)$ & $122(14)$ & $21(20)$ & $1.80 *$ \\
\hline $\begin{array}{l}\text { Lipid-lowering } \\
\text { treatment }\end{array}$ & $613(64)$ & $557(65)$ & $56(53)^{*}$ & 1.09 \\
\hline History of diabetes & $97(10)$ & $74(9)$ & $23(22)^{* * * *}$ & $2.77 * * *$ \\
\hline $\begin{array}{l}\text { History of } \\
\text { hypertension }\end{array}$ & $408(48)$ & $259(42)$ & $42(43)$ & 1.20 \\
\hline $\begin{array}{l}\text { Current smoking } \\
\text { habits }\end{array}$ & $48(5)$ & $42(5)$ & $6(6)$ & 1.17 \\
\hline $\begin{array}{l}\text { Previous smoking } \\
\text { habits }\end{array}$ & $512(59)$ & $444(59)$ & $68(66)$ & 1.24 \\
\hline
\end{tabular}

Values presented are mean value \pm SD or number (\%).

$* p<0.05 ; * * p<0.01$; *** $p<0.001$.

${ }^{a}$ Comparisons made by Wilcoxon signed rank test or Student's $t$-test. RHR: relative hazard rate for all-cause mortality calculated by the single Cox regression model; BMI: body mass index; SBP: systolic blood pressure; DBP: diastolic blood pressure.

patient-years with an average follow-up of $7.35 \pm 3.13$ years (range: $0.45-13.8$ years). The clinical characteristics of the included patients are summarized in Table 1. Overall, the mean age was $60.6 \pm 9.5$ years. Differences between survivors and non-survivors could be found for age, resting systolic blood pressure, statins prescription and a history of diabetes.

Exercise testing variables at baseline and after training are described in Table 2. Mean OUES at baseline was $1760 \pm 586$, corresponding to $70 \pm 19 \%$ of the predicted value, ${ }^{9,26}$ and peak $\mathrm{VO}_{2}$ was $19.7 \pm 5.6 \mathrm{~mL} / \mathrm{kg} /$ minute, or $76 \pm 17 \%$ of the predicted value. ${ }^{6}$ Fourteen of the included patients did not reach a peak RER of $>1.0$ in one of the CPETs.

\section{Training effect}

Altogether, average training attendance was 2.26 times per week. The mean overall training intensity, determined as the ratio of mean exercise heart rate during the last three training sessions and peak heart rate during the post-training exercise test, was $83 \%$ in the total study group (see Table 3 ). There were no differences between survivors and non-survivors regarding training characteristics $(p>0.05)$. The overall training-induced change of the OUES was $255 \pm 368$ $(17 \%)$. The distribution of the training-induced change in OUES is shown in Figure 2. Resting heart rate, resting diastolic blood pressure and almost all exercise variables improved significantly after training. Training-induced changes in exercise variables for the whole group are provided in Table 2. The training-induced changes in gas exchange variables and the differences in responses between survivors and non-survivors are shown in Table 3 . Survivors and non-survivors differed significantly for training-induced changes in peak $\mathrm{VO}_{2}$ and OUES $(p<0.05)$.

\section{Prognostic significance of the OUES}

A total of $105(11 \%)$ patients died at an average of $5.51 \pm 3.15$ years after starting the cardiac rehabilitation program. Causes of death were $\mathrm{CV}$ in 46 patients and non-CV in 59 patients, 45 of whom died of cancer, and the remaining 14 patients died due to other or unknown reasons (official death certificates could not be checked).

The relative hazard rates for all-cause mortality calculated by the single Cox regression model are shown in Tables 1 and 3. Table 4 provides an overview of the relative hazard rates of the post-training OUES for allcause and CV mortality: 1) unadjusted; 2) adjusted for age and gender; 3) adjusted for age, gender and history of diabetes; and 4) adjusted for all previous variables and baseline OUES. The relative hazard rate for the unadjusted post-training OUES was $0.51 \quad(p<0.001)$ for all-cause and $0.41(p<0.001)$ for CV mortality. The relative hazard rate for post-training OUES, after adjustment for all significant covariates, was 0.53 $(p<0.05)$ for all-cause and $0.34(p<0.01)$ for $\mathrm{CV}$ mortality.

In Table 5, the results from the survival analysis with regards to changes in OUES are summarized, both unadjusted and adjusted for significant covariates. The relative hazard rate for post-training OUES, after adjustment for all significant covariates, was 0.54 $(p<0.01)$ for all-cause and $0.37(p<0.05)$ for $\mathrm{CV}$ mortality.

ROC curve analysis revealed an increase of $6 \%$ in OUES with training as an optimal cut-off value with $50 \%$ sensitivity and $63 \%$ specificity. Figure 3 shows Kaplan-Meier survival curves for patients according to an achieved increase in the percentage of the 
Table 2. Training-induced changes in exercise variables.

\begin{tabular}{|c|c|c|c|c|c|}
\hline Variable & Baseline & After training & Absolute difference & Relative difference & $p$-value \\
\hline OUES & $1760 \pm 585$ & $2019 \pm 662$ & $259 \pm 366$ & $17 \pm 24 \%$ & $<0.001$ \\
\hline OUES (\% predicted) & $70.1 \pm 19.5$ & $80.0 \pm 21.0$ & $9.98 \pm 14.7$ & $17 \pm 24 \%$ & $<0.001$ \\
\hline Peak oxygen uptake (mL/minute) & $|56| \pm 475$ & $1889 \pm 559$ & $328 \pm 234$ & $22 \pm 16 \%$ & $<0.001$ \\
\hline Peak oxygen uptake (mL/kg/minute) & $19.7 \pm 5.6$ & $23.9 \pm 6.5$ & $4.16 \pm 3.02$ & $22 \pm 17 \%$ & $<0.001$ \\
\hline $\mathrm{VE} / \mathrm{VCO}_{2}$ slope & $29.6 \pm 5.90$ & $28.5 \pm 5.4$ & $-I . I \pm 4 . I$ & $-2.4 \pm 13 \%$ & NS \\
\hline Peak ventilation (l/minute) & $61.9 \pm 19.0$ & $73.9 \pm 21.8$ & $12.0 \pm 12.8$ & $22 \pm 24 \%$ & $<0.001$ \\
\hline Peak heart rate (beats/minute) & $|25 \pm 2|$ & $|34 \pm 2|$ & $8.75 \pm 13.8$ & $7.8 \pm 12 \%$ & $<0.001$ \\
\hline Peak RER & $1.21 \pm 0.11$ & $1.21 \pm 0.11$ & $-0.001 \pm 0.11$ & $0.4 \pm 10 \%$ & NS \\
\hline
\end{tabular}

Values presented are mean value $\pm S D$.

OUES: oxygen uptake efficiency slope; VE: minute ventilation; $\mathrm{VCO}_{2}$ : carbon dioxide uptake; RER: respiratory exchange ratio.

Table 3. Exercise training data.

\begin{tabular}{|c|c|c|c|c|}
\hline & Overall & Survivor & Non-survivors ${ }^{a}$ & RHR \\
\hline \multicolumn{5}{|l|}{ Exercise training characteristics } \\
\hline & $2.26 \pm 0.47$ & $2.25 \pm 0.47$ & $2.29 \pm 0.49$ & 1.02 \\
\hline Training frequency (times/week) & & & NS & NS \\
\hline & $82.5 \pm 12.1$ & $82.5 \pm 11.9$ & $82.8 \pm 13.3$ & 0.99 \\
\hline Training intensity (\% peak HR) & & & NS & NS \\
\hline \multicolumn{5}{|l|}{ Response to exercise training } \\
\hline Change in peak oxygen uptake (mL/minute) & $328 \pm 234$ & $335 \pm 233$ & $\begin{array}{l}268 \pm 236 \\
(p<0.01)\end{array}$ & $\begin{array}{l}0.02 \\
(0.09-0.53) \\
(p<0.001)\end{array}$ \\
\hline Change in peak oxygen uptake (\%) & $22 \pm 16$ & $22 \pm 16$ & $\begin{array}{l}20 \pm 24 \\
(p<0.05)\end{array}$ & $\begin{array}{l}0.99 \\
(0.98-1.0) \\
(p<0.05)\end{array}$ \\
\hline Change in OUES & $259 \pm 366$ & $269 \pm 360$ & $\begin{array}{l}179 \pm 400 \\
(p<0.01)\end{array}$ & $\begin{array}{l}0.49 \\
(0.29-0.83) \\
(p<0.01)\end{array}$ \\
\hline Change in OUES (\%) & $17 \pm 24$ & $17 \pm 24$ & $\begin{array}{l}12 \pm 25 \\
(p<0.05)\end{array}$ & $\begin{array}{l}0.99 \\
(0.98-0.99) \\
(p<0.05)\end{array}$ \\
\hline Change in $\mathrm{VE} / \mathrm{VCO}_{2}$ slope & $-I . I \pm 4 . I$ & $-I . I \pm 4.2$ & $\begin{array}{l}-0.87 \pm 3.67 \\
\text { NS }\end{array}$ & $\begin{array}{l}1.017 \\
(0.97-1.07) \\
\text { NS }\end{array}$ \\
\hline
\end{tabular}

Values presented are mean value \pm SD or number (\%).

${ }^{a}$ Comparisons made by chi square analysis or unpaired Student's $t$-test.

RHR: relative hazard rate for all-cause mortality, calculated by the single Cox regression model (the $95 \%$ confidence interval is shown in parentheses); HR: heart rate; OUES: oxygen uptake efficiency slope; VE: minute ventilation; $\mathrm{VCO}_{2}$ : carbon dioxide uptake.

predicted OUES of less or more than $6 \%$. The patients who had an increased OUES percentage of less than $6 \%$ were significantly older and had a lower training attendance. Moreover, there were significantly more fatal events in this low-response group: $14 \%$ fatal events in the non-responding group versus $9 \%$ in the group with an OUES increase of $6 \%$ or more.

\section{Prognostic significance of other exercise testing variables}

As shown in Table 3 , the change in peak $\mathrm{VO}_{2}$ due to exercise training was also related to all-cause mortality. The $\mathrm{VE} / \mathrm{VCO}_{2}$ slope did not change with training and the change due to training was not significantly related to all-cause and CV mortality. When the change in the 


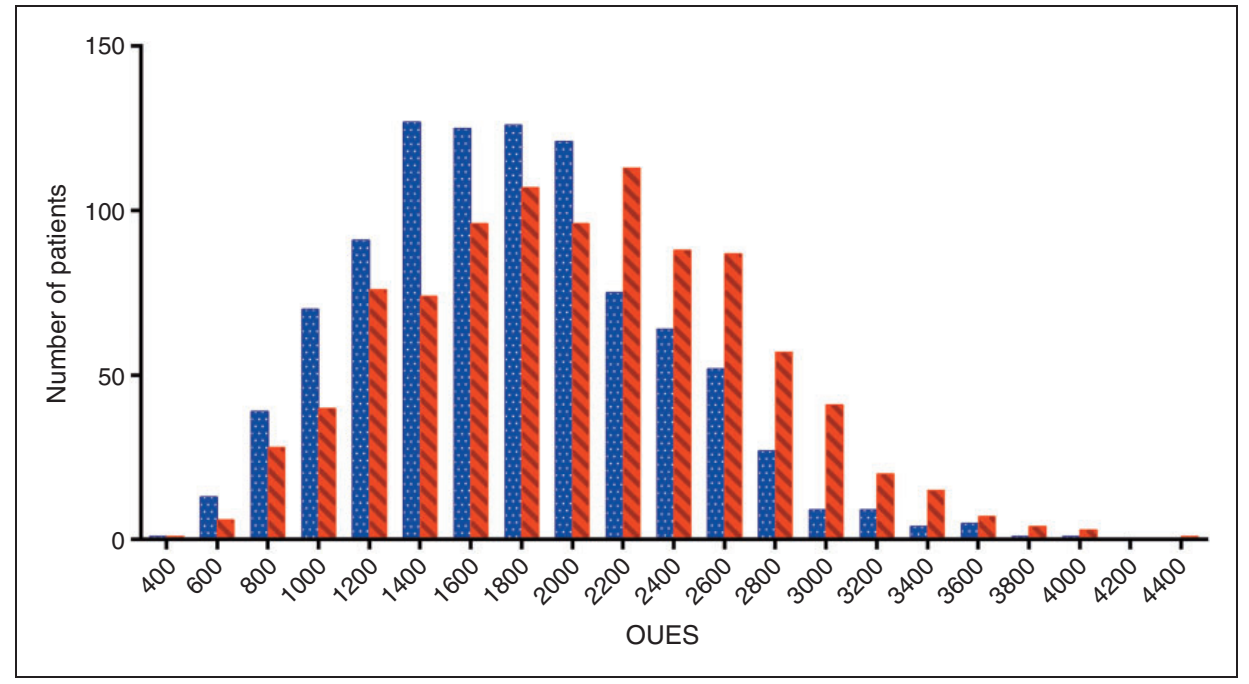

Figure 2. Distribution of the OUES at baseline (blue, dotted bars) and post-training (red, striped bars).

OUES: oxygen uptake efficiency slope.

Table 4. Relative hazard rates and $95 \%$ confidence limits of the post-training oxygen uptake efficiency slope for all-cause and cardiovascular mortality.

\begin{tabular}{lll}
\hline & $\begin{array}{l}\text { All-cause } \\
\text { mortality }\end{array}$ & $\begin{array}{l}\text { Cardiovascular } \\
\text { mortality }\end{array}$ \\
\hline Unadjusted & $\begin{array}{l}0.5 I^{* * *} \\
(0.37-0.70)\end{array}$ & $\begin{array}{l}0.4 I^{* * *} \\
(0.25-0.67)\end{array}$ \\
Adjusted for & & \\
Baseline OUES & $0.43^{* *}$ & $0.28^{* *}$ \\
Baseline OUES and age & $(0.25-0.74)$ & $(0.12-0.65)$ \\
Baseline OUES, & $(0.29-0.90)$ & $0.33^{*}$ \\
age and diabetes & 0.53 & $0.14-0.78)$ \\
\hline
\end{tabular}

Relative hazard rates for all-cause and cardiovascular mortality calculated by the single and multiple Cox regression models; confidence limits are shown in parentheses.

$* p<0.05 ; * * p<0.01$; *** $p<0.001$.

OUES: oxygen uptake efficiency slope.

$\mathrm{VE} / \mathrm{VCO}_{2}$ slope was entered into the model, only the change in OUES remained related to all-cause mortality (hazard ratio: $0.47 ; p<0.05$ ). When change in peak $\mathrm{VO}_{2}$ was also entered into the model, this last parameter was the only determinant of all-cause mortality (hazard ratio: $0.29 ; p<0.05$ ).

In the univariate Cox regression analysis, the posttraining $\mathrm{VE} / \mathrm{VCO}_{2}$ slope and post-training peak $\mathrm{VO}_{2}$ were both related to survival. When entered together with post-training OUES in a multivariate model, only the post-training $\mathrm{VE} / \mathrm{VCO}_{2}$ slope (hazard ratio: 1.062; $p<0.01$ ) and post0training peak $\mathrm{VO}_{2}$ (hazard ratio:
Table 5. Relative hazard rates and $95 \%$ confidence limits of the change in oxygen uptake efficiency slope for all-cause and cardiovascular mortality.

\begin{tabular}{lll}
\hline & $\begin{array}{l}\text { All-cause } \\
\text { mortality }\end{array}$ & $\begin{array}{l}\text { Cardiovascular } \\
\text { mortality }\end{array}$ \\
\hline Unadjusted & $\begin{array}{l}0.49 * * \\
(0.29-0.83)\end{array}$ & $\begin{array}{l}0.34^{* *} \\
(0.16-0.75)\end{array}$ \\
Adjusted for & $0.43^{* *}$ & $0.28^{* *}$ \\
Baseline OUES & $(0.24-0.74)$ & $(0.12-0.65)$ \\
Baseline OUES and age & $0.50^{*}$ & $0.32^{*}$ \\
& $(0.29-0.89)$ & $(0.13-0.78)$ \\
Baseline OUES, & $0.53^{*}$ & $0.34^{*}$ \\
age and diabetes & $(0.30-0.93)$ & $(0.14-0.82)$ \\
Baseline OUES, & $0.54^{*}$ & $0.37^{*}$ \\
age, diabetes & $(0.30-0.95)$ & $(0.15-0.90)$ \\
and diuretics & &
\end{tabular}

Relative hazard rates for all-cause and cardiovascular mortality calculated by the single and multiple Cox regression models; confidence limits are shown in parentheses.

$* p<0.05 ; * * p<0.01$.

OUES: oxygen uptake efficiency slope.

$0.999 ; p<0.01)$ remained related to all-cause mortality, and significance was lost for post-training OUES.

\section{Discussion}

To the best of our knowledge, this is the first study that investigated the prognostic value of the training response of the OUES in a large group of patients with CAD who participated in a cardiac rehabilitation program. Our results show that the OUES at the end of 


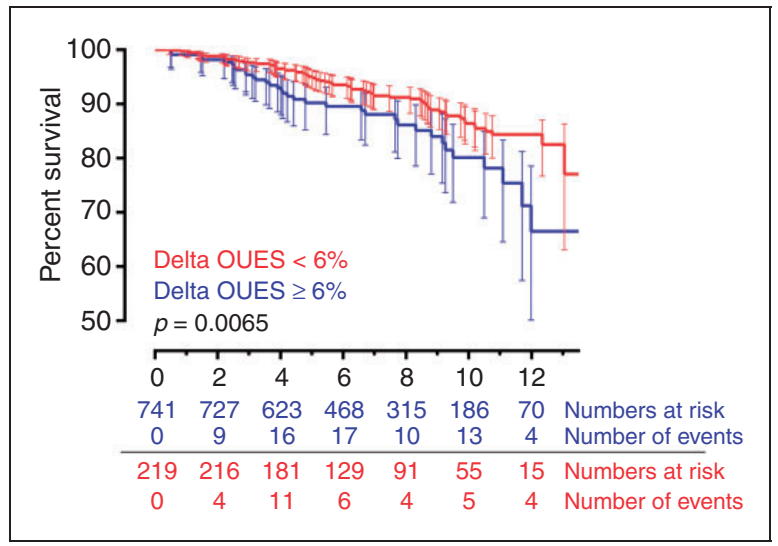

Figure 3. Kaplan-Meier survival curves for the survival of patients with an increase in the percentage of OUES of more or less than $6 \%$.

OUES: oxygen uptake efficiency slope.

3 months of cardiac rehabilitation is more strongly related to outcome than the baseline value. This indicates that cardiac rehabilitation enables us to distinguish patients with a false-negative outcome based on baseline exercise capacity from patients with a truenegative outcome (low baseline exercise capacity and low response to exercise training) who are in need of closer medical follow-up.

In the present study, OUES increased on average by $17 \%$ after a 3 -month cardiac rehabilitation program. An increase in peak $\mathrm{VO}_{2}$ after exercise training is well documented, ${ }^{29-32}$ and our group already demonstrated that the OUES shows a similar response to training in CAD patients. ${ }^{10}$ Furthermore, previous research showed that cardiac rehabilitation reduces the risk for future fatal and non-fatal events in patients with CAD. ${ }^{22,31,33-36}$ This was summarized in several meta-analyses, which showed that the risk for all-cause and CV mortality was significantly lower in cardiac rehabilitation groups compared to control groups. ${ }^{18,31,33,35,38}$ Thus, an increase in exercise capacity is related to a reduction of all-cause and CV events. $^{22,32,34,36,39}$

Regarding submaximal measures of exercise capacity, one study in patients with CAD found an increase in exercise capacity, expressed in metabolic equivalent of the task, of $32 \%$ after a 12 -week cardiac rehabilitation program. They calculated the Duke prognostic risk score, which is a validated risk score that predicts 5-year $\mathrm{CV}$ mortality using data from an exercise tolerance test, and found that the risk for $\mathrm{CV}$ mortality decreased by $33 \%$ among their study participants. ${ }^{39}$ Another study found that each 1 MET (corresponding to $3.5 \mathrm{~mL} / \mathrm{kg} /$ minute $\mathrm{VO}_{2}$ ) increase in submaximal effort was associated with a $34 \%$ reduced risk in mortality. ${ }^{34}$

\section{Training response}

In our study, patients with a training-induced improvement in OUES of less than $6 \%$ were at higher risk of mortality. One reason for a lack of a favorable response to cardiac rehabilitation could be an insufficient training dose. Indeed, our results showed that patients with an increase in exercise capacity of less than $6 \%$ had a significantly lower training attendance compared to those who showed an improved exercise capacity of more than $6 \%$. It therefore seems important to emphasize exercising on a regular base, preferably at least three times a week. However, on the other hand, a low training response can also be a result of underlying pathological mechanisms making it difficult for a patient to improve exercise capacity by training. Determining which parameters relate to an unfavorable response to training might enable us to better adapt the training program according to every patient's needs. Therefore, patients who do not significantly improve in exercise capacity after a training program should be carefully monitored. ${ }^{40}$

There is abundant evidence highlighting the prognostic value of the training-induced changes in peak exercise capacity. Our results also confirm the value of changes in peak $\mathrm{VO}_{2}$ by training and show stronger prognostic value of changes in peak $\mathrm{VO}_{2}$ when compared to changes in OUES. In our study, maximal effort was reached in almost all CPETs, so changes in peak $\mathrm{VO}_{2}$ would be the preferred outcome to focus on. However, in case of sub-maximally executed CPETs, which is the case when tests need to be interrupted because of ischemia, arrhythmias, ICD thresholds, etc., the change in OUES becomes the measure of choice for predicting exercise-induced outcomes.

\section{Post-CR versus baseline values}

After adjusting for baseline OUES, which was a significant covariate, the post-training OUES remained a significant predictor of both all-cause and CV mortality, indicating that the post-CR value is a stronger predictor than the baseline OUES. We showed that an increase of post-training OUES of 100 units is associated with a decreased risk of all-cause and CV mortality of $5 \%$ and $6 \%$, respectively.

Post-training OUES holds prognostic information on its own; however, when the established prognostic exercise markers of peak $\mathrm{VO}_{2}$ and the $\mathrm{VE} / \mathrm{VCO}_{2}$ slope are added to the model, post-training OUES is no longer a marker for all-cause and CV mortality.

\section{Study limitations}

A first limitation of our study consists of the fact that all patients voluntarily chose to participate in the 
cardiac rehabilitation program and might as such constitute a selected population. Second, the female gender was under-represented in the present study. Third, data on possible influencing cofactors such as other medication use, left ventricular ejection fraction, habitual physical activity levels, etc., were not available, which is a result of the retrospective design of this study. Fourth, death certificates could not be checked, resulting in unknown causes of death for a proportion of the studied patients. This might have introduced some bias into the regression analyses.

\section{Conclusion}

Post-CR OUES has stronger prognostic value compared to baseline OUES. The lack of improvement in exercise capacity, as expressed by OUES, after an exercise training program relates to a worse prognosis, resulting in further distinction between patients with favorable and unfavorable prognoses.

\section{Declaration of conflicting interests}

The authors declared no potential conflicts of interest with respect to the research, authorship and/or publication of this article.

\section{Funding}

The author(s) disclosed receipt of the following financial support for the research, authorship, and/or publication of this article: V. A. Cornelissen is supported as a postdoctoral research fellow by the Research Foundation Flanders (FWO); V. A. Cornelissen and R. Buys are supported by a research grant from the FWO; R. Buys received a grant from the Belgian Fund for Cardiac Surgery for her research.

\section{References}

1. Kavanagh T, Mertens DJ, Hamm LF, et al. Peak oxygen intake and cardiac mortality in women referred for cardiac rehabilitation. J Am Coll Cardiol 2003; 42: 2139-2143.

2. Vanhees L, Fagard R, Thijs L, et al. Prognostic significance of peak exercise capacity in patients with coronary artery disease. J Am Coll Cardiol 1994; 23: 358-363.

3. Kavanagh T, Mertens DJ, Hamm LF, et al. Prediction of long-term prognosis in 12169 men referred for cardiac rehabilitation. Circulation 2002; 106: 666-671.

4. Mark DB and Lauer MS. Exercise capacity: the prognostic variable that doesn't get enough respect. Circulation 2003; 108: 1534-1536.

5. Vanhees L, Lefevre J, Philippaerts R, et al. How to assess physical activity? How to assess physical fitness? Eur J Cardiovasc Prev Rehabil 2005; 12: 102-114.

6. Wasserman K, Hansen JE, Sue DY, et al. Normal values. In: Principles of Exercise Testing and Interpretation. 5th ed. 2012, pp.154-180. Philadelphia: Lippincott Williams \& Wilkins.

7. Coeckelberghs E, Buys R, Goetschalckx K, et al. Prognostic value of the oxygen uptake efficiency slope and other exercise variables in patients with coronary artery disease. Eur J Prev Cardiol 2016; 23: 237-244.

8. Baba R, Nagashima M, Goto M, et al. Oxygen uptake efficiency slope: a new index of cardiorespiratory functional reserve derived from the relation between oxygen uptake and minute ventilation during incremental exercise. J Am Coll Cardiol 1996; 28: 1567-1572.

9. Hollenberg $M$ and Tager IB. Oxygen uptake efficiency slope: an index of exercise performance and cardiopulmonary reserve requiring only submaximal exercise. J Am Coll Cardiol 2000; 36: 194-201.

10. Defoor J, Schepers D, Reybrouck T, et al. Oxygen uptake efficiency slope in coronary artery disease: clinical use and response to training. Int J Sports Med 2006; 27: 730-737.

11. Baba R, Tsuyuki K, Kimura Y, et al. Oxygen uptake efficiency slope as a useful measure of cardiorespiratory functional reserve in adult cardiac patients. Eur J Appl Physiol Occup Physiol 1999; 80: 397-401.

12. Van de Veire NR, Van Laethem C, Philippe J, et al. VE/ $\mathrm{VCO}_{2}$ slope and oxygen uptake efficiency slope in patients with coronary artery disease and intermediate peak $\mathrm{VO}_{2}$. Eur J Cardiovasc Prev Rehabil 2006; 13: 916-923.

13. Buys R, Cornelissen V, Van De Bruaene A, et al. Measures of exercise capacity in adults with congenital heart disease. Int $J$ Cardiol 2011; 153: 26-30.

14. Jaussaud J, Aimable L and Douard H. The time for a new strong functional parameter in heart failure: the VE/ $\mathrm{VCO}_{2}$ slope. Int J Cardiol 2011; 147: 189-190.

15. Gademan MG, Swenne CA, Verwey HF, et al. Exercise training increases oxygen uptake efficiency slope in chronic heart failure. Eur J Cardiovasc Prev Rehabil 2008; 15: 140-144.

16. Davies LC, Wensel R, Georgiadou P, et al. Enhanced prognostic value from cardiopulmonary exercise testing in chronic heart failure by non-linear analysis: oxygen uptake efficiency slope. Eur Heart J 2006; 27: 684-690.

17. Baba R, Nagashima M, Nagano Y, et al. Role of the oxygen uptake efficiency slope in evaluating exercise tolerance. Arch Dis Child 1999; 81: 73-75.

18. Taylor RS, Brown A, Ebrahim S, et al. Exercise-based rehabilitation for patients with coronary heart disease: systematic review and meta-analysis of randomized controlled trials. Am J Med 2004; 116: 682-692.

19. Suaya JA, Stason WB, Ades PA, et al. Cardiac rehabilitation and survival in older coronary patients. $J$ Am Coll Cardiol 2009; 54: 25-33.

20. Martin BJ, Hauer T, Arena R, et al. Cardiac rehabilitation attendance and outcomes in coronary artery disease patients. Circulation 2012; 126(6): 677-687.

21. Jolliffe JA, Rees K, Taylor RS, et al. Exercise-based rehabilitation for coronary heart disease. Cochrane Database Syst Rev 2001; 1: CD001800.

22. Oldridge N. Exercise-based cardiac rehabilitation in patients with coronary heart disease: meta-analysis outcomes revisited. Future Cardiol 2012; 8: 729-751.

23. Tsuyuki K, Kimura Y, Chiashi K, et al. Oxygen uptake efficiency slope as monitoring tool for physical training in 
chronic hemodialysis patients. Ther Apher Dial 2003; 7 : 461-467.

24. Van Laethem C, Van de Veire N, De Backer G, et al. Response of the oxygen uptake efficiency slope to exercise training in patients with chronic heart failure. Eur $J$ Heart Fail 2007; 9: 625-629.

25. Vanhees L, Fagard R, Thijs L, et al. Prognostic value of training-induced change in peak exercise capacity in patients with myocardial infarcts and patients with coronary bypass surgery. Am J Cardiol 1995; 76: 1014-1019.

26. Buys R, Coeckelberghs E, Vanhees L, et al. The oxygen uptake efficiency slope in 1411 Caucasian healthy men and women aged 20-60 years: reference values. Eur J Prev Cardiol 2015; 22: 356-363.

27. World Health Organization. [International Classification of Diseases]. Infirm $\mathrm{Fr}$ 1981; 222: 26-28.

28. Allison PD. Survival Analysis Using SAS: A Practical Guide, 2nd ed. Cary, NC: SAS Institute, 2010.

29. Lavie CJ and Milani RV. Effects of cardiac rehabilitation programs on exercise capacity, coronary risk factors, behavioral characteristics, and quality of life in a large elderly cohort. Am J Cardiol 1995; 76: 177-179.

30. Nieuwland W, Berkhuysen MA, Landsman ML, et al. Training effects on peak $\mathrm{VO}_{2}$, specific of the mode of movement, in rehabilitation of patients with coronary artery disease. Int J Sports Med 1998; 19: 358-363.

31. Vanhees L, Fagard R, Thijs L, et al. Prognostic value of training-induced change in peak exercise capacity in patients with myocardial infarcts and patients with coronary bypass surgery. Am J Cardiol 1995; 76: 1014-1019.

32. Pattyn N, Coeckelberghs E, Buys R, et al. Aerobic interval training vs. moderate continuous training in coronary artery disease patients: a systematic review and meta-analysis. Sports Med 2014; 44: 687-700.
33. O'Connor GT, Buring JE, Yusuf S, et al. An overview of randomized trials of rehabilitation with exercise after myocardial infarction. Circulation 1989; 80: 234-244.

34. Feuerstadt P, Chai A and Kligfield P. Submaximal effort tolerance as a predictor of all-cause mortality in patients undergoing cardiac rehabilitation. Clin Cardiol 2007; 30: 234-238.

35. Kavanagh T, Hamm LF, Beyene J, et al. Usefulness of improvement in walking distance versus peak oxygen uptake in predicting prognosis after myocardial infarction and/or coronary artery bypass grafting in men. Am J Cardiol 2008; 101: 1423-1427.

36. Dendale P, Berger J, Hansen D, et al. Cardiac rehabilitation reduces the rate of major adverse cardiac events after percutaneous coronary intervention. Eur $J$ Cardiovasc Nurs 2005; 4: 113-116.

37. Oldridge NB, Guyatt GH, Fischer ME, et al. Cardiac rehabilitation after myocardial infarction. Combined experience of randomized clinical trials. JAMA 1988; 260: 945-950.

38. Prakash M, Myers J, Froelicher VF, et al. Clinical and exercise test predictors of all-cause mortality: results from $>6,000$ consecutive referred male patients. Chest 2001; 120: 1003-1013.

39. Adams BJ, Carr JG, Ozonoff A, et al. Effect of exercise training in supervised cardiac rehabilitation programs on prognostic variables from the exercise tolerance test. $\mathrm{Am}$ J Cardiol 2008; 101: 1403-1407.

40. Tabet JY, Meurin P, Beauvais F, et al. Absence of exercise capacity improvement after exercise training program: a strong prognostic factor in patients with chronic heart failure. Circ Heart Fail 2008; 1: 220-226. 